\title{
Energy Conversion Modes Depending on the Outdoor Temperature for an Air Handling Unit with a Heat Pump
}

\author{
Anton Frik*, Vytautas Martinaitis, Juozas Bielskus \\ Department of Building Energetics, Vilnius Gediminas Technical University, Vilnius, Lithuania
}

Received 04 February 2020; accepted 25 March 2020

\begin{abstract}
Modern air handling units (AHU) are increasingly finding solutions in which the main energy transformers are an air heat pump (HP) and a heat recovery exchanger (HRE). The energy conversion modes of such devices are constantly changing in accordance with the constant change on the state of the outdoor air (temperature, humidity). Flexibility, being able to respond to ever-changing ambient air parameters, is an important feature of energy transformation component mode control. The overall seasonal efficiency of the air handling unit depends on this. In this work, a thermodynamic analysis of the characteristic energy transformations of the air handling unit is performed, linking the outdoor and ventilated indoor air and HP refrigerant states, flow rates and component loads. Such parametric analysis with respect to the changing outdoor air temperature allowed to clearly reveal, through various indicators, the influence of the individual components on the operating efficiency of the air handling unit. Combinations of parameters have been obtained that enable the selection of the optimal control concept for the energy conversion mode of the components in the air handling unit (component loads, fluids state parameters and flow rates) over a wide range of outdoor air temperatures.
\end{abstract}

Keywords: integrated heat pump in air handling unit, performance of air handling unit, variable outdoor temperature.

\section{Introduction}

Although there is a policy in most countries to improve the energy performance of buildings, the average energy consumption per person in the construction sector has not changed much since 1990 (International Energy Agency, 2017). The progress was not so fast as to offset the increase in area (3\% per year) and the growing demand for energy in buildings where the main users are HVAC systems. They consume half of the energy consumed in the EU (European Commission, 2016).

Heat consumption in new buildings is significantly reduced thanks to the introduction of measures to reduce heat transfer in accordance with the EPBD (Directive on the energy performance of buildings) (European Parliament and of the Council, 2010). That is why ventilation and air conditioning are becoming the dominant energy-consuming systems in buildings. In addition, the number of offices in Lithuania and around the world is growing, and energy consumption is increasing here. About a quarter of energy consumption in the building sector can be attributed to office buildings, which account for more than $70 \%$ of the final energy consumption for HVAC systems (Schlomann \& Kleeberger, 2015). HVAC systems, as well as new materials, new monitoring and automatic control technologies and their new algorithms demonstrate a rapidly growing interest in achieving higher energy efficiency (Jouhara \& Yang, 2018). Namely, HVAC systems require new intelligent technological solutions that can provide the required indoor air quality and efficiently consume energy for this.

This requires new knowledge that opens opportunities for more efficient products that directly contribute to the achievement of the strategic goals of the EU and Lithuania to reduce energy consumption, use renewable energy sources and increase energy efficiency. Renewable energy, such as photovoltaic cells (PV) and wind, is usually generated in the form of electricity. In this situation, the heat pump (HP) becomes one of the potentially major energy transformers in HVAC systems. The use of HP for building heating systems is not an innovation, but their use in ventilation systems is less common. Recently, the situation has begun to change, and more and more manufacturers of air handling units (AHU) (e.g., FläktGroup, Mandik, Dantherm A/S, Komfovent, VENTS) offer AHU with built-in (integrated) heat pumps. It should be noted that heat pump energy requirements, efficiency (coefficient of performance $\mathrm{COP}$ ), and management of these indicators are closely related to various problems of smart grid management (Chen et al., 2018; Lund et al., 2015), which include such integral indicators like storage capacity, building energy flexibility, demand responds and etc.

${ }^{*}$ Corresponding author. E-mail: anton.frik@vgtu.lt 
One of the criteria for reducing the energy requirements of buildings during the modernization of their HVAC systems is the seasonal effectiveness of these systems. In this case, their integral efficiency over the period used (for example, the heating season) depends on both high nominal instantaneous efficiency factors and their ability to maintain them in a wide range of changes in energy demand (Panteli \& Mancarella, 2015). The longest part of the season is occupied by the long-term average (only a few or several degrees lower than indoors) and a constantly changing ambient temperature. This determines the level of the seasonal COP of heat pump (COP HP SEZ).

It is obvious that the operating modes of the heat pump should be changed depending on the constantly changing ambient temperature. It is also important to decide at what temperature of the outside air it is necessary to achieve the highest nominal values, while maintaining the functionality of the system at other temperatures. For this purpose, modern heat pump cycle controllers are used - a variable speed compressor (VSCM) and an adjustable position throttle valve (TV), a combination of controlling these components (heat pumps controlled by a modulator/inverter). This decision once allowed to increase the seasonal COP. These solutions continue to be developed, trying to find solutions that would increase COPHP.S. Modular control (continuous control) is the best control mode for the heat pump compressor integrated in the ventilation system. Because this mode allows you to adapt to constantly fluctuating air parameters and provide the required heating power. In addition, as demonstrated by other researchers (e.g., Aprea et al., 2006; Dongellini et al., 2017), variable speed operation is more effective than stepped and ON/OFF operation. Aprea et al. (2006) in his work carried out research (comparison) of heat pump (air-water) operating in ON/OFF and modulating modes. The results show that continuous regulation allows a $20 \%$ reduction in electricity costs. Energy savings were mainly due to the decrease in the compression ratio (degree) during the modulation phase (Aprea et al., 2006). Dongellini et al. (2017) the results of the heat pump operation modes study show that the seasonal efficiency of the heat pump operating in continuous control mode is higher by $8.3 \%$ and $15.4 \%$ respectively compared to heat pumps operating in step and ON/OFF modes (Dongellini et al., 2017). In addition, modulating control minimizes the number of compressor on/off cycles, which positively affects its service life.

There are also attempts to optimize the operation of the heat pump compressor from the programming side as well. Recently, Zachary Lee et al. (2019) demonstrated a variable speed heat pump control optimization model in their work. This model uses a machine learning method to predict the magnitude of the heat load and the outside temperature, as well as mixed-integrated programming to optimize compressor control. This made it possible to offer optimal heat pump operation schedules for the selected area and reduce electricity costs by $9 \%$ (Lee et al., 2019).

The increase in efficiency is achieved by combining the choice of the highest load with modulation systems and on/off control (Bagarella et al., 2016), where the use of storage capacity reduces the number of on/off cycles of the heat pump compressor. Clauß and Georges (2019) investigates the influence of the modeling complexity of the heat pump control in the context of demand response and building energy flexibility by analyzing a heat pump along with the entire heating and hot water system (Clauß \& Georges, 2019). Genetic algorithms are used to optimize $C O P_{H P S E Z}$ by combining the maximum heat pump load, operating volume of compressor, and system performance (Lee et al., 2018). However, even these new studies are not aimed at solving the problem of assessing the capabilities of control thermodynamic HP cycle (not to be confused with HP on/off cycles). Such studies exist (Jensen \& Skogestad, 2005), but they are specific and not directly related to the features of HVAC systems.

The review presented above shows that most of the work on improving the efficiency of a heat pump addresses conventional, well-known and widely used heat pump controls and their optimal performance. Little attention is paid to the thermodynamic cycle of the heat pump and the search for new ways to modify and control it. This is a potential direction that could improve the efficiency of the heat pump.

Thus, in this situation, two main aspects can be distinguished to help approach this issue:

1. Finding the optimal thermodynamic cycle for heat pump, dependent on the outdoor temperature;

2. The search for thermodynamically based new technological possibilities to extend the degrees of freedom of heat pump control.

The main aim of this work is to approach the optimal, highly energy-efficient thermodynamic cycle of the heat pump (integrated into the AHU) in a wide range of outdoor air parameters, to determine the influence of individual components of the AHU on the cycle and the overall energy efficiency of the unit.

\section{Analytical description of the process}

The article analyzes the processes of energy transformations in the AHU, the main energy transformers of which are heat pump (HP) and heat exchanger (HRE). A schematic example of an AHU is shown in Figure 1. HP consists of condenser $(\mathrm{CN})$, evaporator $(\mathrm{EV})$, compressor $(\mathrm{CM})$ and throttle valve (TV). Along with two fans (supply - Fs and exhaust $-\mathrm{Fe}$ ) and the aforementioned ventilation heat recovery exchanger (HRE) we have an AHU. The interaction parameters of these components under typical AHU operating conditions are analyzed in this work. In the context of this study the characteristic operating conditions include states of the ambient and ventilated room air and HP refrigerant states, primarily characterized by temperatures. They can be converted to other complementary or derivative parameters (enthalpies, entropies, coenthalpies, pressures, etc. of a particular refrigerant). 
Coefficient of performance of the AHU $\left(C O P_{A H U}\right)$ is considered as the main efficiency indicator. The COP of $\mathrm{AHU}$ is practically consistent with the COP of HP concept and is calculated using the formula:

$$
C O P_{A H U}=\frac{\dot{Q}_{A H U}}{\dot{E}_{A H U}^{+}},
$$

where: $\dot{E}_{A H U}^{+}$- is the energy flow rate supplied from outside of the AHU's thermodynamic system, both as work and as heat. In our case, this is the energy used by the fans and the CM. $\dot{Q}_{A H U}$ - is heat flow rate required to ensure that air is supplied at the desired temperature. Heat flow rate is calculated using equation:

$$
\dot{Q}_{A H U}=\dot{M}_{V} c_{p a}\left(T_{R}-T_{e}\right)
$$

where: $\dot{M}_{V}$ - air flow rate, $\mathrm{kg} / \mathrm{s} ; c_{p a}-$ specific heat of air, $\mathrm{J} /(\mathrm{K} \cdot \mathrm{kg}) ; T_{R}$ - room air temperature, $\mathrm{K} ; T_{e}-$ environment temperature, $\mathrm{K}$.

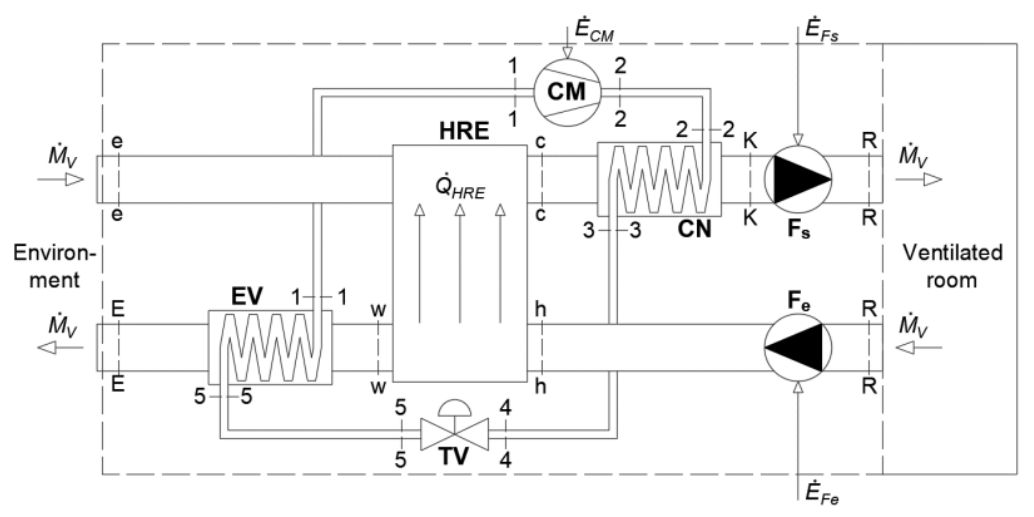

Figure 1. Analysed Air Handling Unit (AHU)

Operation of the analyzed AHU (Figure 1). The amount of air $M_{V}$ required for ventilation is supplied to and extracted from the ventilated room. Outdoor air at $T_{e}$ temperature enters the HRE, where it heats from $T_{e}$ to $T_{c}$. Then, the air in the HP condenser $(\mathrm{CN})$ is heated to temperature $T_{K}$, then slightly warmed in the supply fan and supplied to the room in temperature $T_{R}$. From the room extracted air of temperature $T_{R}$ is warmed in the exhaust fan to temperature $T_{h}$. Then the air in the HRE gives its heat to the supply air, after which its temperature drops to the temperature $T_{w}$. After this, the air continues to transfer its heat in the HP evaporator (EV), while cooling to a temperature $T_{E}$.

The $p$ - $h$ diagram (Figure $2 \mathrm{a}$ ) shows the cycle processes which there are in heat pump refrigerant-filled circuit. In an evaparator refrigerant boils and evaporates (5-1) under isobaric pressure $P_{E V}$ and isothermal temperature $T_{E V i z o t}$. Refrigerant vapor can be superheated $\Delta t_{s h}$ for several degrees but may remain in the dry saturated state $T_{1}$ (Figure 2a). Then the refrigerant is compressed in the compressor (1-2) into the $P_{C N}$ pressure superheated vapor state $T_{2}$. This compression occurs slightly to the right of the ideal isoentropic process, depending on the internal isoentropic efficiency of the $\mathrm{CM}\left(\varepsilon_{i C}\right)$. The temperature of the refrigerant rises up to several tens degrees of Celsius. Then the superheated refrigerant vapor enters the condenser $(\mathrm{CN})$ and isobarically delivers heat flow (2-4) required to heat the air from $T_{c}$ to $T_{K}$. In the condenser, the refrigerant cools to the dry saturated vapor state $T_{3}$. At the beginning of the $\mathrm{CN}$, the refrigerant cools to the dry saturated vapor state $T_{3}$. Then it condenses in an isobaric and isothermal process at a temperature of $T_{C N i z o t}$. After that, refrigerant isoentropically expands from $P_{C N}$ to $P_{E V}$ and cools to the temperature of the $\mathrm{EV}$ isotherm $T_{5}=T_{1}$.

Processes occur at variable temperatures but within a relatively limited range of those temperatures. The AHU must provide the heat flow, determined by Eq. (2), for fresh air intended for the ventilation of the room. Thermohydrodynamic processes (in particular heat transfer, transfer rates) in each of the heat exchangers (HRE, CN, EV) are considered similar. The energy balance equations for these heat exchangers are given below (3-5).

Energy Balance equation for the condenser $(\mathrm{CN})$ :

$$
\dot{Q}_{C N}=\dot{M}_{f}\left(h_{2}-h_{4}\right)=\dot{M}_{V}\left(h_{K}-h_{c}\right)=\dot{M}_{V} c_{p a}\left(T_{K}-T_{c}\right) \text {, }
$$

where $\dot{M}_{f}$ is flow rate of refrigerant in HP. The qualities of the refrigerant are numerically important, but it is assumed that their influence on the device processes is no different than in other thermodynamic reverse cycle cases. The refrigerant R32 is used for this study. 
Energy Balance equation for the evaporator $(\mathrm{EV})$ :

$$
\dot{Q}_{E V}=\dot{M}_{f}\left(h_{1}-h_{5}\right)=\dot{M}_{V}\left(h_{w}-h_{E}\right)=\dot{M}_{V} c_{p a}\left(T_{w}-T_{E}\right) .
$$

Energy Balance equation for the heat recovery exchanger (HRE):

$$
\dot{Q}_{H R E}=\dot{M}_{V}\left(h_{h}-h_{w}\right)=\dot{M}_{V}\left(h_{c}-h_{e}\right)=\dot{M}_{V} c_{p a}\left(T_{h}-T_{w}\right)=\dot{M}_{V} c_{p a}\left(T_{c}-T_{e}\right) .
$$

In the calculations, it is assumed that air enters the HRE at an outside temperature $T_{e}$. Thus, the thermal efficiency of the HRE is calculated by the formula:

$$
\varepsilon_{T}=\frac{T_{h}-T_{w}}{T_{h}-T_{e}} \text { or } \varepsilon_{T}=\frac{T_{c}-T_{e}}{T_{h}-T_{e}} .
$$

The heat transfer processes occurring in the condenser and evaporator of the heat pump occur when the state of air and the refrigerant changes, their temperature changes are shown in Figure 2b, c.

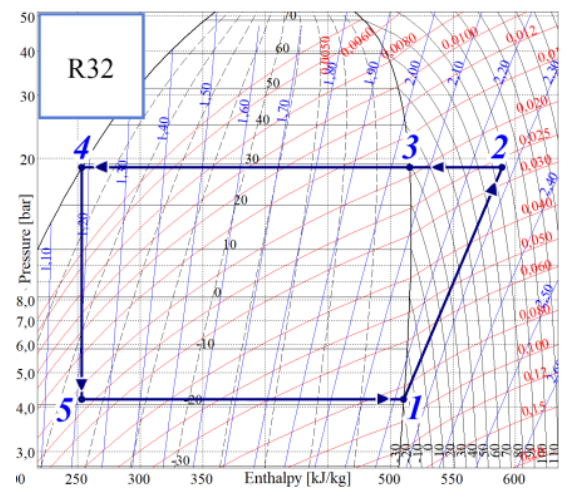

a)

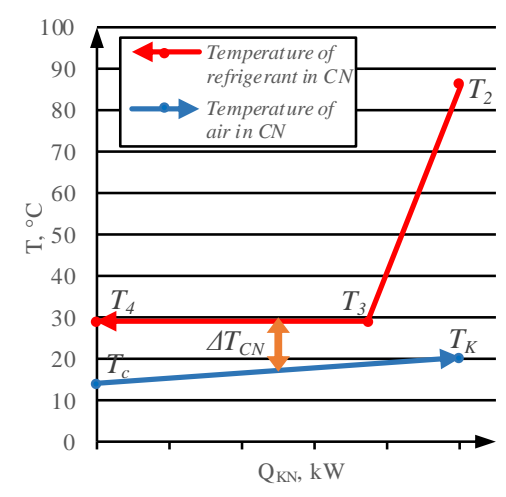

b)

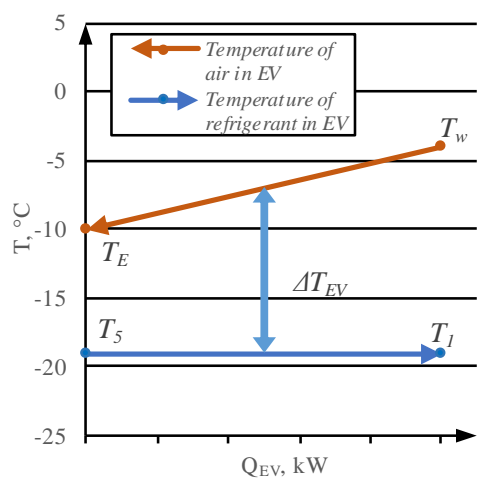

c)

Figure 2. a) Thermodynamic cycle of a HP in $p$ - $h$ diagram; b) Temperature changes in $\mathrm{CN}$; c) Temperature changes in EV

The heat transfer processes are described by similar equations for both $\mathrm{CN}$ and $\mathrm{EV}$ at their respective specific heat flow rates $(A k)_{C N}$ and $(A k)_{E V}$. Heat flow between air and refrigerant in CN (Eq. (7) and EV (Eq. (8):

$$
\begin{aligned}
& \dot{Q}_{C N}=(A k)_{C N} \Delta T_{C N} ; \\
& \dot{Q}_{E V}=(A k)_{E V} \Delta T_{E V},
\end{aligned}
$$

where: $\Delta T$ - temperature difference of heat transfer, $\mathrm{K} ;(A k)$ - specific heat flow rate of heat exchanger.

Using energy balance equation for the $\mathrm{CN}$ and $\mathrm{EV}$ (Eq. (3) and Eq. (4), respectively), the heat transfer temperature difference $\Delta T$ in the following heat exchangers (9-10) is expressed:

$$
\begin{aligned}
& \Delta T_{C N}= \frac{\dot{M}_{V} c_{p a}\left(T_{K}-T_{c}\right)}{(A k)_{C N}} ; \\
& \Delta T_{E V}=\frac{\dot{M}_{V} c_{p a}\left(T_{w}-T_{E}\right)}{(A k)_{E V}} .
\end{aligned}
$$

The dependencies of the variation of isotherms in the $p$ - $h$ diagram and heat transfer temperature differences are related by the energy balance and heat transfer equations. To simplify the calculations, it is assumed that the temperature of the refrigerant does not change over the entire length of the $\mathrm{CN}$ and $\mathrm{EV}$, and there are no "refractive" points such as $T_{3}$ (Figure $2 \mathrm{~b}$ ). They would still be in the real process, but their impact on the outcome of this exercise is not significant. The resulting CN and EV isotherms Eqs (11-12) and the HP Eq. (13) are shown below.

$$
T_{C N i z o t}=\frac{T_{c}+T_{K}}{2}+\Delta T_{C N}=\frac{T_{c}+T_{K}}{2}+\frac{\dot{M}_{V} c_{p a}\left(T_{K}-T_{c}\right)}{(A k)_{C N}} ;
$$




$$
\begin{gathered}
T_{E V i z o t}=\frac{T_{w}+T_{E}}{2}-\Delta T_{E V}=\frac{T_{w}+T_{E}}{2}-\frac{\dot{M}_{V} c_{p a}\left(T_{w}-T_{E}\right)}{(A k)_{E V}} ; \\
\frac{(A k)_{E V}}{(A k)_{C N}}=\frac{\Delta T_{C N}}{\Delta T_{E V}} \frac{C O P_{H P}-1}{C O P_{H P}}
\end{gathered}
$$

where: $C O P_{H P}-$ is the coefficient of performance of the HP. $C O P_{H P}$ can be calculated using equation:

$$
C O P_{H P}=\frac{\dot{Q}_{C N}}{\dot{E}_{H P}^{+}} .
$$

The independent parameters that result from the functionality of the unit are the air flow $M_{V}$, its specific heat $c_{p a}$, the constant $T_{R}$ temperature supplied to the room and the extract air at the same temperature. Also independent is the thermal effectiveness $\varepsilon_{T}$ of HRE. It determines the change in temperature $T_{c}, T_{w}$ in the equations below. The variable parameters depend on the continuously changing ambient air temperature $T_{e}$. The reordered equations expressing the $\mathrm{CN}$ isotherm and temperature difference values of in AHU integrated HP are given below.

Equation of the $\mathrm{CN}$ isotherm and its temperature difference:

$$
\begin{gathered}
T_{C N i z o t}=\frac{T_{h}\left(1+\varepsilon_{T}\right)+T_{e}\left(1-\varepsilon_{T}\right)}{2}+\frac{\dot{M}_{V} c_{p a}\left(1-\varepsilon_{T}\right)\left(T_{h}-T_{e}\right)}{(A k)_{C N}} ; \\
\Delta T_{C N}=T_{C N i z o t}-\frac{\varepsilon_{T} T_{h}+T_{K}+T_{e}\left(1-\varepsilon_{T}\right)}{2} .
\end{gathered}
$$

The following is the equation for the isotherm of the EV:

$$
T_{E V i z o t}=T_{h}-\varepsilon_{T}\left(T_{h}-T_{e}\right)-\Delta T_{E V}\left(\frac{(A k)_{K N} \frac{\Delta T_{C N}}{\Delta T_{E V}} \frac{C O P_{H P}-1}{C O P_{H P}}}{2 \dot{M}_{V} c_{p a}}+1\right) \text {. }
$$

At this stage of solving problems, a restriction is introduced:

$$
\Delta T_{C N}=\Delta T_{E V}
$$

The temperature of the air after the evaporator, i.e. exhausted from the unit:

$$
T_{E}=\left(T_{h}\left(1-\varepsilon_{T}\right)+\varepsilon_{T} T_{e}-\frac{\Delta T_{E V}(A k)_{E V}}{\dot{M}_{V} c_{p a}}\right) .
$$

In this paper the following assumptions have been made:

1. Indoor and outdoor air is dry, and the mass flow rate of supply and exhaust air is the same and constant. $\left(M_{V}=\right.$ const $)$

2. AHU is well insulated (adiabatic), air and refrigerant receive or release heat only through heat exchangers (CN, EV, HRE) or fans $\left(\mathrm{F}_{\mathrm{e}}\right.$ ir $\mathrm{F}_{\mathrm{s}}$ ).

3. The power of Fe and Fs is selected from the recommended specific fan power (SFP) index, expressed in $\mathrm{W} / \mathrm{m}^{3} / \mathrm{s}$.

4. It is assumed that, the heat transfer temperature difference $\Delta T$ in the $\mathrm{CN}$ and $\mathrm{EV}$ is equal (Eq. (17).

5. There are no heat transfers to the air in the room.

6. It is assumed that the changes in air temperatures influenced by $\mathrm{F}_{\mathrm{e}}$ and $\mathrm{F}_{\mathrm{s}}$ are estimated by equating that all of their power is used to heat the air.

7. There is no refrigerant sub-cooling in $\mathrm{CN}$ or super-heating in $\mathrm{EV}$

8. It is assumed that there are no "refractive" points such as $T_{3}$ (Figure 2b) (the temperature of the refrigerant does not change over the entire length of the $\mathrm{CN}$ and $\mathrm{EV}$ ).

\section{Results and discussions}

Given the multiparametric nature of the analytical description of the processes under study, the search for optimal combinations is carried out using parametric analysis. Some parameters in the analytical model are variables, but this does not apply to a real unit (for example, specific heat flow of heat exchangers). Changes in other parameters can only 
be implemented using their control algorithm, which guarantees relatively high and stable performance rates. From a thermodynamic point of view, it is advisable to evaluate the sensitivity of the above parameters to the distance between the refrigerant isotherms.

The solutions of the analytical description equations are not certain and require additional conditions (assumptions, constraints, adjustments). As can be seen from Figure $2 \mathrm{~b}$ and according to formulas 3 and 4 , the heat flows of $\mathrm{CN}$ and EV depend on the refrigerant flow $\dot{M}_{f}$ and the positions of the isotherms $T_{C N i z o t}=T_{4}=T_{3}$ ir $T_{E V i z o t}=T_{5}=T_{1}$ (Figure 2b) and their enthalpies. On the other hand, the difference in temperature between the CN and EV isotherms determines the compressor power, the efficiency of the HP and the AHU as a whole. Based on this, alternatives for analysis are formed by choosing the variations of $T_{C N i z o t}$ and $T_{E V i z o t}$. They do not provide refrigerant sub-cooling in CN or super-heating in EV. Also, the main characteristics of AHU used to calculate all alternatives are listed in Table 1.

Parametric analysis of the above set of equations is presented in the article with 2 alternatives. The first alternative assumes that the refrigerant temperatures in the HP condenser and evaporator are fixed and do not vary with outdoor air temperature, and the characteristic parameters of these heat exchangers $A k_{C N}$ and $A k_{E V}$ are variable. In the second alternative the inverse case is chosen - the characteristic parameters of the heat exchangers $A k_{C N}$ and $A k_{E V}$ are fixed, but the refrigerant temperature in them changes depending on the outdoor air temperature.

In addition, the parametric analysis of the first alternative determines the influence of the HRE on the overall energy efficiency of the AHU.

Table 1. AHU calculations data

\begin{tabular}{|l|c|}
\hline \multicolumn{1}{|c|}{ Parameter } & Value \\
\hline Room air temperature (supply air temperature) & $20^{\circ} \mathrm{C}$ \\
\hline Environment temperature range & $-20 \ldots 15^{\circ} \mathrm{C}$ \\
\hline Air flow rate & $500 \mathrm{~m}^{3} / \mathrm{h}$ \\
\hline Effectiveness of HRE, $\varepsilon \mathrm{T}$ & 0.8 \\
\hline Isentropic efficiency of the compressor of the HP & 0.8 \\
\hline Specific fan power & $250 \mathrm{~W} /\left(\mathrm{m}^{3} / \mathrm{s}\right)$ \\
\hline
\end{tabular}

\section{First alternative}

The first alternative evaluates the change in the parameters of the AHU when the HP is operating at constant temperatures of the isotherms of the $\mathrm{CN}$ and $\mathrm{EV}$, relative to the outside temperature. To recognize the problem, it is assumed that $T_{C N i z o t}=30{ }^{\circ} \mathrm{C}, T_{E V i z o t}=-30{ }^{\circ} \mathrm{C}$. In the parametric analysis of the first alternative, the parameters $(A k)_{C N}$ and $(A k)_{E V}$ are variable.

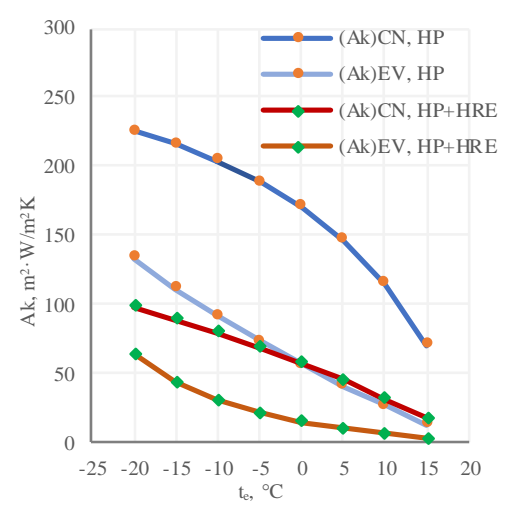

Figure 3. Specific heat flow rates of $\mathrm{CN}$ and EV depending on outdoor air temperature $T_{e}$

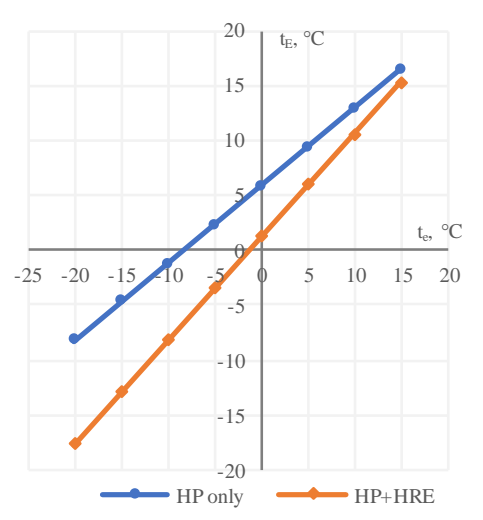

Figure 4. Temperature of exhaust air from AHU depending on outdoor air temperature $T_{e}$

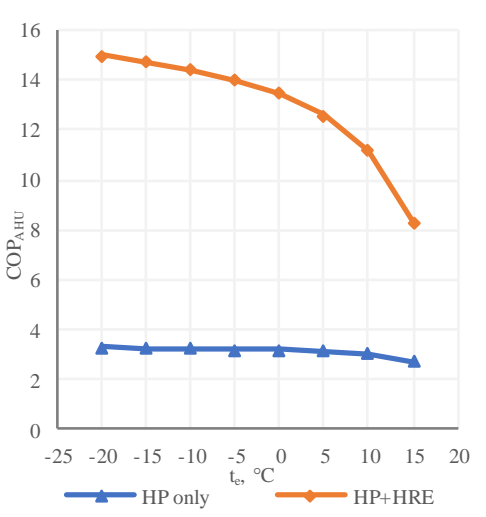

Figure 5. Coefficient of performance $\left(C O P_{A H U}\right)$ of AHU ( $1^{\text {st }}$ alternative $)$ depending on outdoor air temperature $T_{e}$

Figure 3 shows the indicators of the heat transfer process in heat exchangers of HP (CN and EV). Two versions of the AHU are considered in this alternative: when the AHU has only one power transformer - an integrated heat pump ("HP" in Figure 3) and when the unit has two energy transformers working together - the integrated heat pump and heat recovery exchanger ("HP+HRE" in Figure 3). Their specific heat flow rate $(A k)_{C N}$ and $(A k)_{E V}$ are expressed from the above equations $(3,4,5,7,8)$. They decrease with increasing outside temperature $T_{e}$, as well as non-linearly and differently in the condenser and evaporator. Numerical solutions show this, but they physically represent the size of heat exchangers that do not change in a real AHU. It can also be noted that in the first version ("HP"), which uses 
only a HP, the specific heat flow rates of the heat exchangers are significantly higher than the corresponding rates in the AHU where HP and HRE are used together ("HP+HRE").

The temperature of the exhaust air from the AHU indirectly indicates the system's ability to utilize the energy of the exhaust air efficiently (to heat the supply air). Figure 4 shows the change of the temperature $\left(T_{E}\right)$ of the exhaust air from the AHU. Informal logic says that a solution than air throws out at the lowest possible temperature (if not below ambient temperature) is considered to be more valuable. We have this in the case when two energy transformers are used in the AHU - HP and HRE.

Dependences of changes in $C O P_{A H U}$ of the analyzed AHUs are presented in Figure 5. It is seen that the $C O P_{A H U}$ of the unit using only the HP is close to 3 in the entire analyzed temperature range. In the case of the second version of the AHU ("HP+HRE"), this value changes. The $C O P_{A H U}$ decreases with increasing outdoor temperature $T_{e}$, but this value is significantly higher than that of a system with only HP. Thus, ignoring the HRE in AHU using a HP (for example, due to its compactness) adversely affects the overall $C O P_{A H U}$.

\section{Second alternative}

The second alternative is formed after an initial analysis of the numerical results of the first option. First of all, the focus is on changes in the resulting $(A k)_{C N},(A k)_{E V}$ of heat exchangers (CN and EV). Technically, the CN and EV of HP have constant geometric shapes and sizes, but under operating conditions of AHU (i.e., first of all, the FLT (first law of thermodynamics) between its components) they are changing in the conditions of calculation of the first alternative. The dimensions of the heat exchangers $(\mathrm{CN}, \mathrm{EV})$ can be selected for a specific AHU, so that the functionality of the whole unit is not lost. They will simply be selected no less than the highest value obtained in the calculations (as it is usually done in engineering practice).

An AHU with HRE and integrated HP is selected for further analysis.

After analyzing the results of the first alternative, this logical sequence is selected for the second alternative. At given isotherm temperatures $\left(T_{C N i z o t 0}=30{ }^{\circ} \mathrm{C}, T_{E V i z o t}=-30{ }^{\circ} \mathrm{C}\right)$ and at a design temperature $T_{e 0}$ corresponding to the maximum heat demand in the selected calculation range, the $(A k)_{C N O}$ is calculated using formulas 15 and 16 . So, at the design temperature $T_{e 0}$, we have $Q_{C N O}=(A k)_{C N O} \Delta T_{C N O}$. For these conditions $\Delta T_{C N}$ and $\Delta T_{E V}$ are found, it is assumed that $\Delta T_{E V O}=\Delta T_{C N O}$ (Eq. (19). As a result of this choice, the specific heat flow rate of the EV $\left((A k)_{E V O}\right)$ is expressed from Eq. (13) and becomes a certain value. These specific heat flow rates of the $\mathrm{CN}$ and $\mathrm{EV}$ are taken as constant values in the following calculations of this alternative. Due to the assumptions made, the initial temperature of the EV isotherm increased slightly compared to $T_{E V i z o t 0}$, but this does not significantly affect the final trends.

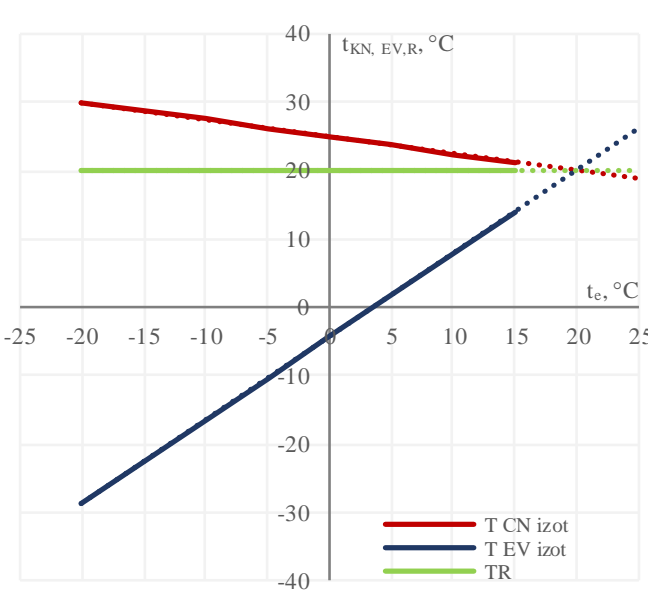

Figure 6. Refrigerant temperatures $T_{C N i z o t}, T_{E V i z o t}$ and room air temperature depending on outdoor air temperature $T_{e}$

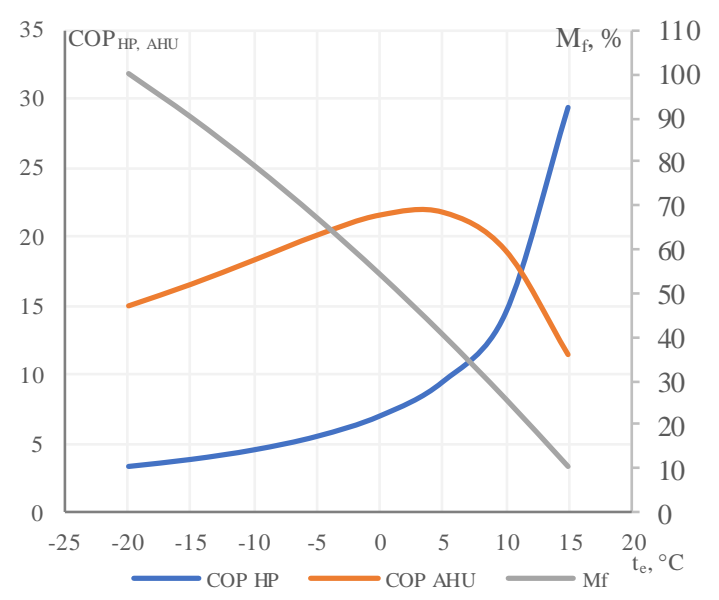

Figure 7. Coefficient of performance (COP) of HP, AHU $\left(2^{\text {nd }}\right.$ alternative) and refrigerant flow rate depending on outdoor air temperature $T_{e}$

Figure 6 shows the temperature trends of the isotherms $\mathrm{CN}$ and EV. Refrigerant temperatures (extensions of their lines) intersect at room temperature $T_{R}\left(20^{\circ} \mathrm{C}\right) . T_{C N i z o t}$ temperature changes were limited by the task - the supply air should be sufficiently heated, i.e. $T_{C N i z o t}>T_{R}$. The temperatures of the isotherms approach each other (the EV isotherm changes more). In this case, the HP control algorithm is consistent with the processes of other AHU components, the variable speed CM and TV should work according to this control algorithm.

Figure 7 shows the change in coefficient of performance of AHU (COPAHU, Formula 1) and integrated HP $\left(C O P_{H P}\right)$ as a function of outdoor air temperature. The relative refrigerant flow rate is also shown in the graph. We can see in the graph that the overall efficiency of AHU, whose energy transformers are HRE and HP, is quite high throughout the temperature range under consideration. In addition, the maximum is at the prevailing outdoor temperatures during the heating season. With increasing outdoor temperature, $C O P_{A H U}$ and $C O P_{H P}$ also increase. However, from 
$T_{e}=\sim 3{ }^{\circ} \mathrm{C}$, the COP of AHU begins to decline, although the COP of HP continues to rise. Due to the decreasing heat flow required for heating the supply air, the flow rate of the refrigerant $\left(M_{f}\right)$ circulating in the HP circuit and the electric energy consumption of HP are reduced. The amount of energy used by the fans is constant throughout the temperature range. In addition, from $T_{e}=\sim 3{ }^{\circ} \mathrm{C}$, the power of the fans starts to exceed the electrical power of HP. This is negatively reflected in the $\mathrm{COP}$ of $\mathrm{AHU}$, starting at this temperature, although $C O P_{H P}$ has a positive trend (Figure 7).

The results of the parametric analysis show that the overall energy efficiency of AHU of the first alternative, where the temperature of the refrigerant in the $\mathrm{CN}$ and $\mathrm{EV}$ is constant but the parameter $A k$ of $\mathrm{CN}$ and EV varies, is lower than in the second alternative, where the $A k$ values of $\mathrm{CN}$ and $\mathrm{EV}$ are fixed and the refrigerant temperatures in the $\mathrm{CN}$ and $\mathrm{EV}$ vary. This proves that the choice of constant isotherms (or operating close to them) is not an acceptable solution for heat pumps not only from the technical side, but also from the side of energy efficiency.

\section{Conclusions}

A parametric analysis of the AHU with HP and HRE characteristic energy transformations showed the potential for efficiency improvement in process control choices.

1. Ignoring HRE on HP-powered AHUs has been shown to negatively impact overall performance, as the first alternative shows.

2. Parametric analysis showed that the temperature change of the refrigerant in the cycle (in particular EV) should be related not only to $T_{e}$ (as already used in modern solutions), but also to the temperature in $T_{R}$.

3. The resulting trend in CN and EV temperature variations reveals the features of HP's integrated AHU control that allows for high overall AHU performance. Such management is not applied, and its practical feasibility has not been explored.

4. The selection of optimal AHU sizes for engineering solutions should include the economic evaluation of those solutions. This would allow for a more reasonable approach to the specific values of $(A k)_{C N}$ and $(A k)_{E V}$, considering not only climatic but also economic conditions. In such a case, such evaluations should still satisfy the analytical parameter dependencies established in the article.

\section{References}

Aprea, C., Mastrullo, R., \& Renno, C. (2006). Experimental analysis of the scroll compressor performances varying its speed. Applied Thermal Engineering, 26(10), 983-992. https://doi.org/10.1016/j.applthermaleng.2005.10.023

Bagarella, G., Lazzarin, R., \& Noro, M. (2016). Sizing strategy of on-off and modulating heat pump systems based on annual energy analysis. International Journal of Refrigeration, 65, 183-193. https://doi.org/10.1016/j.ijrefrig.2016.02.015

Chen, Y., Xu, P., Gu, J., Schmidt, F., \& Li, W. (2018). Measures to improve energy demand flexibility in buildings for demand response (DR): A review. Energy and Buildings, 177, 125-139. https://doi.org/10.1016/j.enbuild.2018.08.003

Clauß, J., \& Georges, L. (2019). Model complexity of heat pump systems to investigate the building energy flexibility and guidelines for model implementation. Applied Energy, 255, 113847. https://doi.org/10.1016/j.apenergy.2019.113847

Dongellini, M., Abbenante, M., \& Morini, G. L. (2017). A strategy for the optimal control logic of heat pump systems: impact on the energy consumptions of a residential building. Paper presented at the Proceedings of the $12^{\text {th }}$ IEA Heat Pump Conference 2017.

European Commission. (2016). An EU strategy on heating and cooling 2016. Brussels.

European Parliament and of the Council. (2010). Directive 2010/31/EU of the European Parliament and of the Council of 19 May 2010 on the energy performance of buildings OJ L 153, 18.6.2010 (pp. 13-35).

International Energy Agency. (2017). Energy efficiency indicators 2017. IEA Publications.

Jensen, J. B., \& Skogestad, S. (2005). Control and optimal operation of simple heat pump cycles. Computer Aided Chemical Engineering, 20, 1429-1434. https://doi.org/10.1016/S1570-7946(05)80080-X

Jouhara, H., \& Yang, J. (2018). Energy efficient HVAC systems. Energy and Buildings, 179, 83-85. https://doi.org/10.1016/j.enbuild.2018.09.001

Lee, S. H., Jeon, Y., Chung, H. J., Cho, W., \& Kim, Y. (2018). Simulation-based optimization of heating and cooling seasonal performances of an air-to-air heat pump considering operating and design parameters using genetic algorithm. Applied Thermal Engineering, 144, 362-370. https://doi.org/10.1016/j.applthermaleng.2018.08.078

Lee, Z., Gupta, K., Kircher, K. J., \& Zhang, K. M. (2019). Mixed-integer model predictive control of variable-speed heat pumps. Energy and Buildings, 198, 75-83. https://doi.org/10.1016/j.enbuild.2019.05.060

Lund, P. D., Lindgren, J., Mikkola, J., \& Salpakari, J. (2015). Review of energy system flexibility measures to enable high levels of variable renewable electricity. Renewable and Sustainable Energy Reviews, 45, 785-807. https://doi.org/10.1016/j.rser.2015.01.057

Panteli, M., \& Mancarella, P. (2015). Influence of extreme weather and climate change on the resilience of power systems: impacts and possible mitigation strategies. Electric Power Systems Research, 127, 259-270. https://doi.org/10.1016/j.epsr.2015.06.012

Schlomann, B., \& Kleeberger, H. (2015). Energieverbrauch des Sektors Gewerbe, Handel, Dienstleistungen (GHD) in Deutschland für die Jahre 2011 bis 2013 (pp. 1-320). 